\title{
Correction to: Racial disparities in surveillance mammography among older breast cancer survivors
}

\author{
Jimmitti Teysir ${ }^{1}$ (I) $\cdot$ Nana Gegechkori ${ }^{2} \cdot$ Juan P. Wisnivesky ${ }^{1}$ Jenny J. Lin ${ }^{1}$
}

Published online: 5 June 2019

○) Springer Science+Business Media, LLC, part of Springer Nature 2019

\section{Correction to: Breast Cancer Research and Treatment https://doi.org/10.1007/s10549-019-05250-8}

In the original publication of the article, under the Methods section, second paragraph, the sentence that reads as "We excluded 3047 patients ... surgical treatment (see Fig. 1)" should read as "We excluded 3047 patients who did not identify as black or white, 5395 who were not initially diagnosed with stage 0 -III cancer or were missing stage or residence data, 2573 patients who passed away within 18 months of diagnosis, and 4716 patients who did not undergo primary surgical treatment (see Fig. 1)".

Figure 1 was published incorrectly in the original version. The corrected Fig. 1 is given below.

Publisher's Note Springer Nature remains neutral with regard to jurisdictional claims in published maps and institutional affiliations.

The original article can be found online at https://doi.org/10.1007/ s10549-019-05250-8.

Jimmitti Teysir

jimmitti.teysir@icahn.mssm.edu

1 Division of General Internal Medicine, Icahn School of Medicine at Mount Sinai, One Gustave L. Levy Place, Box 1087, New York, NY 10029, USA

2 Division of Internal Medicine, Maimonides Medical Center, 4802 10th Avenue, New York, NY 11219, USA 
Fig. 1 Flowchart for selection of study participants
Diagnosed with stage 0 -IV breast cancer between 2000-2011 ( $N=59,648)$

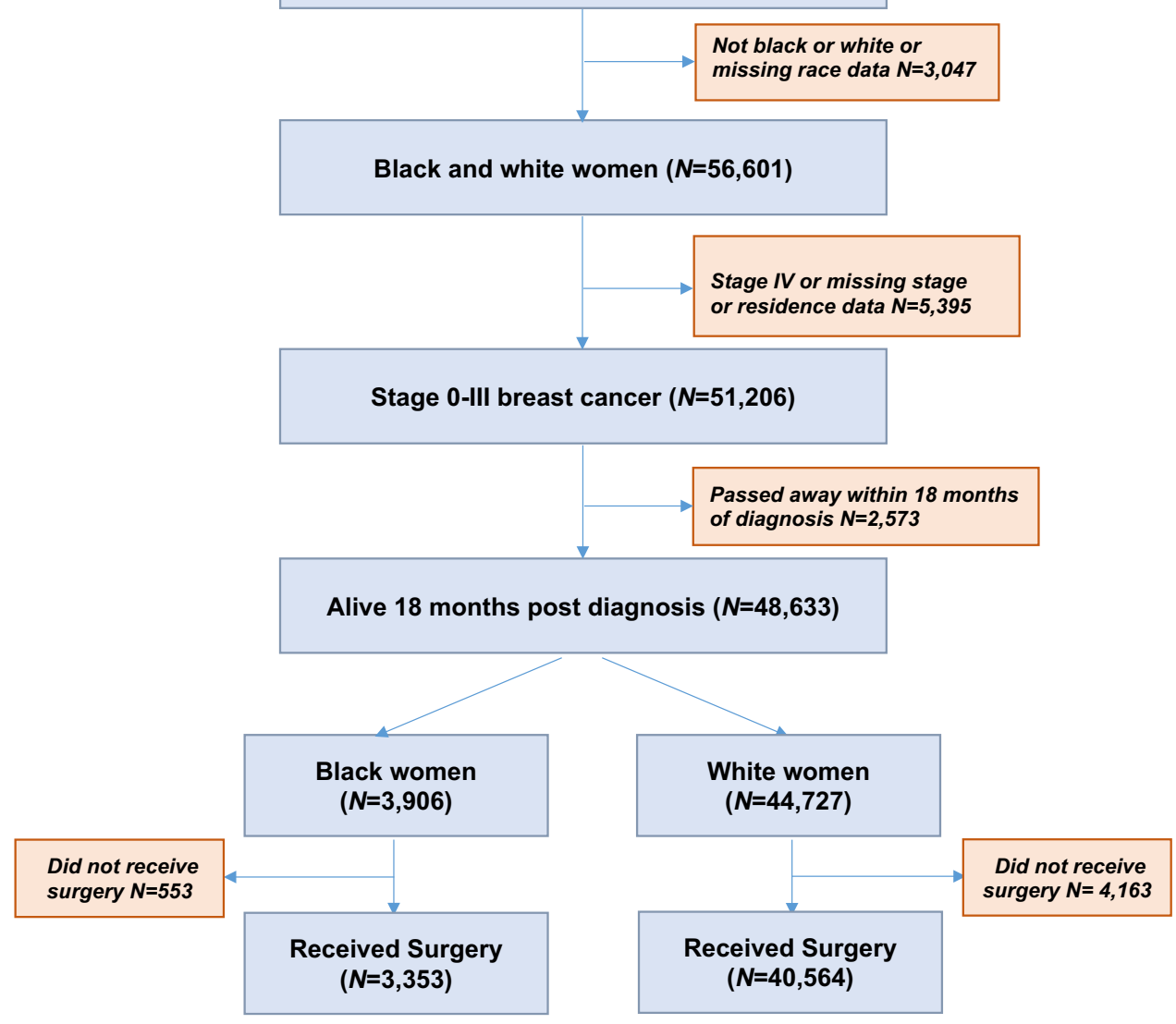

